\title{
COMPLICAÇõES NEUROLÓGICAS POR OSTEOMAS DOS SEIOS PARANASAIS. A PROPÓSITO DE UM CASO DE PNEUMATOCELE EXTRADURAL POR OSTEOMA DO SEIO FRONTAL
}

\author{
R. Melatagno Filho * \\ Moysés Cutin **
}

Os osteomas primitivos dos seios paranasais podem evoluir silenciosa e assintomàticamente, podendo ser encontrados casualmente em exames radiográficos visando qualquer outra condição mórbida. Em outros casos, en. tretanto, êsses tumores podem, em sua expansão lenta, exceder do seio onde estão alojados e determinar fenomenologia de maior ou menor gravidade, que exige imediata intervenção cirúrgica. $O$ caso que registramos exemplifica bem a possibilidade de um osteoma do seio frontal vir a determinar hemiparesia devido à erosão da parede posterior e do assoalho do seio frontal, com formação de pneumatocele extradural.

ObServação - J. A., 38 anos, branco, brasileiro, casado, motorista. Registro 18.216-00. O paciente procurou, pela primeira vez o Ambulatório de Neurologia do I.A.P.E.T.C., em 21 de setembro de 1950, referindo que, hí aproximadamente 30 dias, começara a sentir dor de cabeça intensíssima, sem localização precisa, mas predominando na linha mediana; nunca teve vômitos ou distúrbios visuais. Paralelamente à cefaléia, o doente notou diminuição da fôrça muscular nos membros do hemicarpo direito. Paulatinamente a cefaléia desapareceu totalmente e o paciente procurou o Ambulatório de Neurologia queixando-se apenas da hemiparesia direita. Dos antecedentes familiais, nada há a registrar. Quanto aos antecedentes pessoais, há referências a um traumatismo na região frontal esquerda há alguns anos, mas sem gravidade e sem lesão perceptível. Operado de hérnia inguino-escrotal. Blenorragia há 4 anos. Jamais contraiu cancros venéreos. A reação de Wassermann no sangue sempre foi negativa.

Exame físico geral - Bulhas cardíacas normais. Tensão arterial $108-70 \mathrm{rmm}$ de mercúrio. Ausência de sinais periféricos de arteriosclerose. Septo nasal regular, com desvio, na parte alta, para a esquerda. Pela transluminação, aspecto sombrio do seio frontal esquerdo. Exame neurológico - Psiquismo íntegro. Marcha é ligeiramente ceifante, com tendência a manter o membro superior direito em semiflexão. Ausência de qualquer tipo de afasia ou de apraxia. Não há paralisia completa de nenhum grupo muscular; contudo a motilidade voluntária dos membros direitos é muito mais reduzida em relação à do lado esquerdo; as manobras de Mingazzini, Barré, Raimiste e dos braços estendidos revelam franca tendência ì queda dos membros do lado direito. Ligeira ataxia com dismetria, disdiacococinesia e positividade da prova de Stewart-Holmes à direita, talvez dependente do intenso déficit motor nesse lado. Hipertonia do tipo piramidal no membro superior direito, predominando nos grupos musculares flexores; no membro inferior direito,

* Assistente da Clínica Neurológica da Fac. Med. da Univ. de São Paulo (Prof. A. Tolosa). Neurologista do I.A.P.E.T.C.

** Assistente de Clínica Otorrinolaringológica da Fac. Med. da Univ de São Paulo (Prof. A. Paula Santos). Otorrinolaringologista do I.A.P.E.T.C. 
durante a marcha, nota-se hipertonia de ação nos grupos extensores; entretanto, quando o paciente é examinado em decúbito dorsal verifica-se aumento da extensibilidade e da passividade no membro inferior direito. Reflexos clônicos profundos mais vivos à direita; à direita, o reflexo patelar manifesta o caráter pendular. Ausência dos reflexos de Rossolimo e Mendel-Bechterew. Ausência do sinal de Babinski. Clono do pé direito. Sensibilidedes superficial e profunda íntegras. () exame dos nervos cranianos foi completamente negativo.

Exames complementares - Exame neuro-ocular: Acuidade visual em $\mathrm{AO}=1$; motricidade extrínseca e intrínseca nornais: fundos oculares normais. Exame do líqüido cefalorraquidiano: Punção suboccipital; pressão inicial 15 (Claude); quadro liqüórico inteiraniente dentro dos limites da normalidade (Dr. J. Batista dos Reis). Reação de Wassermann e Kahn no sangue negativas. Radiografias do crânio (fig. 1): Desenho vascular muito acentuado; sela turca com caracteres e dimensões normais; seio esfenoidal bastante desenvolvido; seio frontal ocupado em sua porção mediana por massa opaca sem estrutura bem definida, contínua com a parede posterior e assoalho do seio, com aspecto de osteoma; glândula pineal calcificada, não deslocada no plano sagital. Imagem aérea volumosa, ocupando a maior porção do
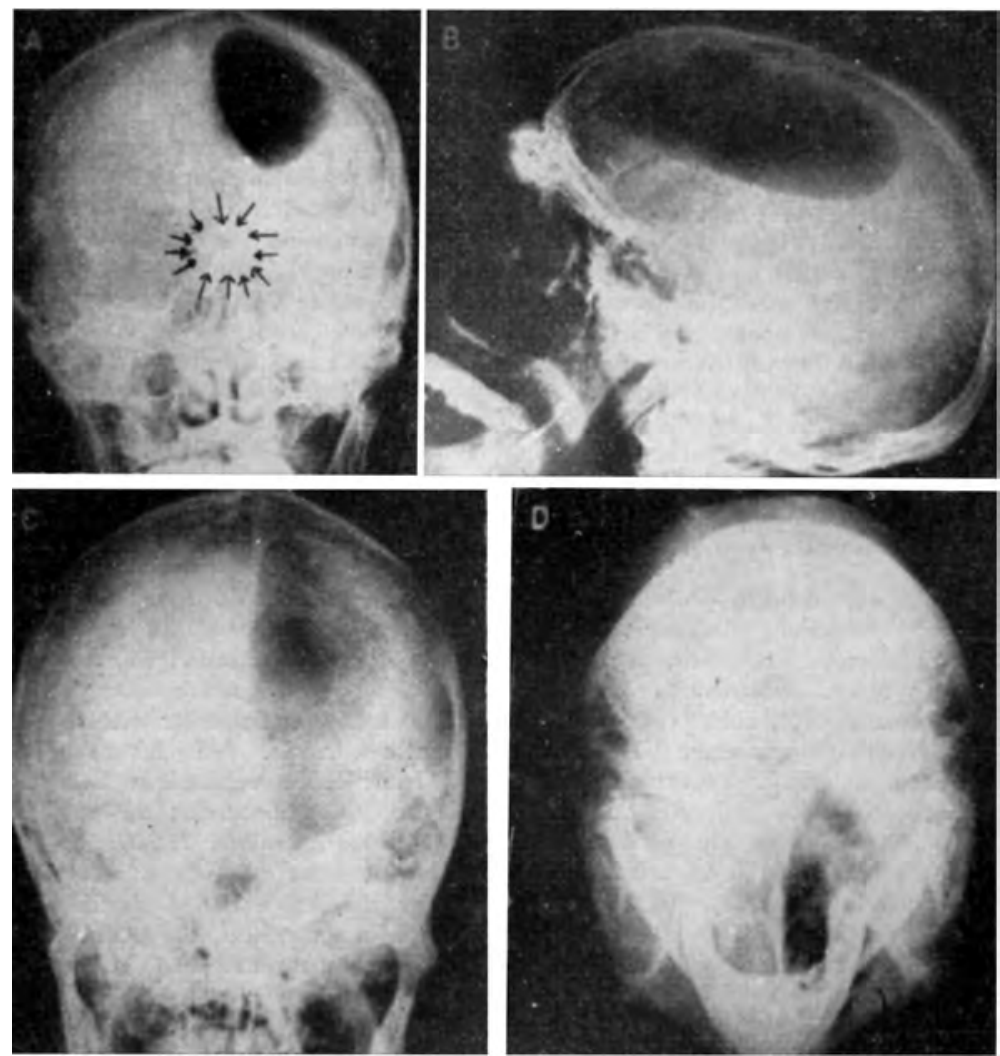

Fig. I - Caso J. A. Osteoma do seio frontal esquerdo e grancie bôlsa de ar no hemicrânio esquerdo. Em $\mathrm{C}$, incidência oblíqua dc Towne; em $\mathrm{D}$, incidência de Hirtz. 
hemicrânio esquerdo; pneumatocele (extradural?). Os cortes planigráficos realizados paralelamente ao plano sagital, revelam a presença de osteoma do seio frontal, com erosão da parede posterior do seio, nos cortes realizados a 4 e $5 \mathrm{~cm}$ de um plano paralelo ao plano sagital e passando pela eminência parietal esquerda (Dr. A. Clemente dos Santos Filho). Eletrencefalograma: "O registro das regiões parieto-occipitais mostra um ritmo de base formado por um ritmo alfa moderadamente organizado. Não foram registradas ondas anormais. Há a assinalar uma assimetria: maior amplitude das ondas nas regiões fronto-centro-temporal esquerda. A hiperpnéia não produziu modificação sensível. Em conclusão: há uma assimetria com maior amplitude das ondas nas regióes fronto-centro-temporal esquerda. Como não foram registradas ondas anormais, não há elementos para um diagnóstico definitivo (Dr. A. Conse). Hemograma: leucócitos em número normal; ligeiro desvio para a esquerda dos neutrófilos.

Diante do diagnóstico de um osteoma que, perfurando a parede posterior do seio frontal, permitiu a formação de uma coleção aérea extradural, decidimos pela intervenção cirúrgica, que foi praticada em 11 de outubro de 1950.

Laudo operatório: Escofedal intramuscular. Anestesia loco-regional. Incisão na região supraciliar esquerda. Tábua óssea normal. Com escopo e martelo, foi ressecada a parede anterior do seio. Encontrou-se massa tumoral ússea ocupando 2/3 do seip, deixando livre o têrço externo. Mucosa sinusal espessada; pequena quantidade de secreção mucosa. O tumor estava fixo. Ressecada pequena porção externa com pinça sacabocado, foi verificado que o tumor mergulhava através de uma botoeiza da parede posterior do seio na cavidade craniana. $O$ tumor expandia-se dentro da caixa craniana de tal maneira a obrigar à ressecção de parte da parede posterlor do seio, para expor todo seu contôrno. O tumor estava prêso na altura do ósteo e foi fàcilmente extraído pois seu pedículo era fino. A abertura da parede posterior do seio de forma circular inedia cêrca de $2,5 \mathrm{~cm}$ de diâmetro; através dela via-se dura mater íntegra, com batimentos. Aplicação de sulfa em pó, sutura, dreno de borracha. Medicação geral; penicilina e dihidrostreptomicina, hipnóticos e analgésicos. Retirado o dreno no terceiro dia. Alta hospitalar no oitavo dia, decorrendo o pós-operatório sem qualquer incidente.

Exame anátomo-patológico - O tumor media $3,3 \times 3,4 \times 3 \mathrm{~cm}$ (fig. 2) e deslocava $10 \mathrm{~cm}^{3}$ de água. A parte do tumor que penetrava na cavidade craniana tinha uma superfície polida, brilhante como esmalte. O exame histológico mostron tratar-se de tecido ósseo de aspecto denso (eburnizado); espaços haversianos de

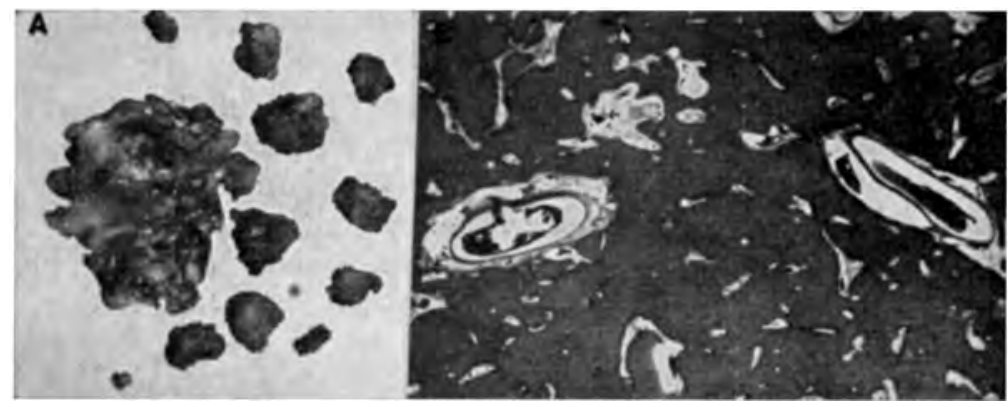

Fig. 2 - Caso J. A. Em A, tumor ósseo retirado em diversos fraymentos; no bloco maior, a porção mais lisa, à esquerda, corresponde à parte do osteoma que se projetava intracranialmente. $\mathrm{Em} \mathrm{B}$, microfotografia: tecida ósseo de aspecto denso (eburnizado); espaços haversianos de tamanhos variáveis com vasos sanguíneos congestos. Osteoma ebúrneo (Leitz x 100). 
tamanhes variáveis, com vasos sangüineos congestos. Osteoma ebúrneo (Dr. G. Elejalde).

Evolução - Já no segundo dia de operação, referia o paciente ter mais livre a movimentação dos membros direitos. Apenas 10 dias após a intervenção, fizemos revisão de suas condições neurológicas: Psiquismo íntegro. Ligeiríssima diminuição da fôrça muscular no dimídio direito, apenas perceptivel em músculos normalmente pouco potentes. Manobras deficitárias negativas. Coordenação muscular perfeita. Ausência de qualquer sinal cerebelar. Reflexos profundos nos membros inferiores vivos e simétricos. Nos membros superiores, os reflexos predominam em intensidade, muito ligeiramente, no lado direito. Tono normal. Ausência de sinal de Babinski. Reflexos cremastéricos e cutâneo-abdominais normais. Ausência de clono e automatismos. Sensibilidade normal. Nervos cranianos indenes.

Revimos o paciente em 17 de novembro de 1950, sendo o exame neurológico inteiramente negativo. Solicitamos novas radiografias no crânio que se mostraram perfeitamente normais, tendo havido reabsorção total da coleção aérea extradural.

\section{COMENTARIOS}

\section{1 - Aspectos otorrinolaringológicos dos osteomas frontais.}

Novick" dá a definição anátomo-clínica de osteoma: "tumor ósseo, benigno, de crescimento lento, encapsulado, ligado ao ou incluído no osso, do qual provém", ponderando que, sob o ponto de vista clínico, pode não ser benigno devido à proximidade de estruturas importantes. Nosso caso exemplifica bem essa possibilidade.

Dos osteomas dos seios paranasais, o do seio frontal é o mais freqüente. A idade de seu aparecimento é difícil determinar devido à evolução lenta e muitas vêzes silenciosa até ser denunciado por uma complicação ou por um achado fortuito de exame radiográfico. O osteoma é mais encontradiço no homem que na mulher; pode surgir na juventude, sendo que $\mathrm{Ar}$ mitage $^{2}$, em estudo estatístico, verificou que $50 \%$ dos casos se manifesta na juventude e $80 \%$ antes da idade de 50 anos. Patriarca e Rossello ${ }^{3}$ encontraram um osteoma de seio paranasal em doente com 75 anos de idade. Childray ${ }^{4}$, em 3.510 radiografias de seios da face, descobriu osteomas em $0,42 \%$ dos casos.

Begley e Hallberg ${ }^{5}$ reuniram as doutrinas sôhre as causas dêsses tumores em três grupos - cmbriołógico, traumático e infeccioso. Tilmanns ${ }^{6}$ notou a predileção de se desenvolverem em ossos de origem endocondral; mesmo os do seio frontal, que são de origem membranosa, proviriam da região do óstio, zona de junção dêste osso com o etmóide, de modo que o tumor se desenvolveria à custa dêste último osso. 0 traumatismo seria um fator importante, se não como causa única pelo menos como agente desencadeante. Esse parecer é esposado por Gerber, Culbert, Garretson, Fetissof, Carmody e Fenton ${ }^{6}$. 0 paciente por nós estudado relatou forte traumatismo na região frontal há alguns anos. Álguns autores quiseram atribuir papel etiológico à infecção, tendo em vista a concomitância das sinusites dos seios, sedes de osteomas. No paciente que estudamos havia sinusite hiperplástica. Cremos que isto deve, necessàriamente, produzir-se com um tumor 
implantado no óstio, obstando em maior ou menor grau a drenagem, fator preponderante na defesa sinusal, como é universalmente admitido.

A dôr de cabeça é o sintoma mais comum; entretanto, como no caso presente, pode não existir enquanto não haja complicação. Os sintomas decorrem da invasão das regiōes contíguas. A êsse propósito, muito ilustrativa é a estatística de Begley ${ }^{5}$, em 40 casos; estenderarr-se para as regiōes vizinhas 27, sendo 9 no etmóide, 6 na órbita, 4 para a parede anterior do seio perfurando-a, 4 para o seio frontal oposto, 2 para a parede posterior e 2 para a cavidade nasal.

Pela erosão da parede posterior do seio frontal surgem complicações neurológicas, que serão detalhadamente consideradas abaixo; pela invasão da parede anterior provocam deformidades visíveis; pela penetração na órbita produzem exoftalmos, proptose, diplopia; pela obstrução do conducto naso-frontal determinam mucocele e piocele.

Não há acôrdo quanto à indicação da intervenção cirúrgica, enquanto o tumor não provoca complicações. A escola francêsa é pela extirpação imediata do osteoma, desde que o diagnóstico seja firmado. Os inglêses e americanos têm tendência a contemporizar, em expectativa quanto à evolução. Beck ' refere que $48 \%$ dos casos não operádos morrem de complicação. Decidida a operação, é aconselhável a abordagem por via mais ampla possível, a fim de permitir a visualização máxima do tumor. Às vêzes, há necessidade de fragmentar o tumor, sendo de bom alvitre evitar de fazê-lo com escropo e martelo, pois pode-se provocar fraturas irradiadas, como, por exemplo, para a lâmina do etmóide. Se a consistência do tumor permitir, com pinças sacabocados resolve-se satisfatòriamente o problema. Entretanto, se o osteoma é ebúrneo, atinge-se o fim combinado com trepano. Fivita-se, com manobras cuidadosas, o ducto nasofrontal, sob pena de sobrevirem complicações infecciosas no seio frontal.

Foi com esta orientação que agimos no nosso paciente. Mas, há casos que podem suscitar o problema de saber se o tumor deve ser extirpado por técnica otorrinolaringológica ou neuro-cirúrgica. Boulat ${ }^{22}$ procurou estahelecer a indicação nêste sentido: Os osteomas pequenos, sem complicações, seriam da alçada dos otorrinolaringologistas. Os mais volumosos, pela necessidade de mutilações, podem determinar deformações plásticas quando usada a técnica transinusal; a neuro-cirurgia com retalho ósteo-plástico evita esta possibilidade. Os tumores com expansão intra-craniana, em que há necessidade de descolar a dura mater, devem ser extirpados por neuro-cirurgiōes, por via craniana. Berger ${ }^{22}$, baseando-se em observações pessoais e em revisão da literatura, crê que êstes casos são bem sucedidos nas mãos dos otorrinolaringologistas. A deformação torna-se mínima, quando é respeitado o rebôrdo orbitário; com vantagem de poder-se melhor tratar a sinusite concomitante e fazer drenagem, se necessária, mais ampla do conduto naso-frontal, explorando pelo nariz a sua permeabilidade. Petit Dutaillis, para resolver a sinusite, preconiza a ablação em massa da mucosa sinusal descolada até o óstio como um saco, aí pediculizada e ressecada após ter 
sido amarrada. Benjamins e Verbeek ${ }^{16}$, em um caso semelhante ao nosso, fizeram, mediante uma incisão ao longo do supercílio e outra vertical, uma ressecção ósteo-plástica de forma triangular compreendendo a parede anterior do seio e parte da calota craniana vizinha.

E' ponto pacífico que os casos com complicações subdurais, são do domínio da neuro-cirurgia.

A casuística nacional é pobre, mas - como diz David Sanson ${ }^{9}$ - essa escassez decorre da raridade da afecção. Temos conhecimento, na literatura brasileira, além do caso de Sanson, de um de Renato Machado ${ }^{10}$, um de Nascimento ${ }^{11}$, um de Caiado de Castro. Este último raso foi apenas comunicado e não escrito, segundo Capistrano Pereira ${ }^{12}$.

\section{2 - Complicações neurológicas dos osteomas dos seios paranasais.}

Desenvolvendo-se muito lentamente, à custa de ossificação metaplástica do tecido conjuntivo e de deposição do tecido ósseo de neoformação pela mucosa paranasal, que age como periósteo (Brunner e Spiesman ${ }^{13}$ ), o osteoma pode romper as paredes do seio onde está incluído e vir a determinar sintomas neurológicos. Entretanto, essas eventualidades são raras.

As complicações neurológicas dos osteomas dos seios frontais podem ser assépticas ou sépticas, quer apenas inicialmente, quer durante tôda a evolução da doença. Como frisam Brunner e Spiesman "3, uma complicação intra-craniana inflamatória pode ocorrer se o osteoma não ocupar todo o seio onde está alojado e a porção não ocupada se infeccionar. Como o próprio osteoma dificulta a drenagem, o material séptico tende a se abrir para dentro do crânio. Se o tumor ósseo perfurar a dura mater, a infecção é levada para as leptomeninges e, eventualmente, para o próprio tecido cerebral, com formação de abscessos. Teed ${ }^{8}$ encontrou entre os 321 casos de osteomas de seios registrados na literatura até 194.1, 9 casos de abscessos cerebrais e um de meningite, esta última ocorrendo após a sinusotomia. Dos 4 casos de Cushing ${ }^{14}$, dois faleceram de meningite, sendo um após a intervenção cirúrgica.

Outras vêzes - como ocorreu com nosso paciente - todo o processo neurológico evolui na ausência de qualquer infecção. A sintomatologia varia, então, conforme a direção do desenvolvimento do tumor. Se a expansão se der para o lado, o tumor poderá invadir a órbita, causando perturbações que exigem também intervenção cirúrgica. Quando o osteoma cresce para trás, interessando a parede posterior ou o assoalho do seio frontal, poderá determinar um pertuito entre o tumor ósseo e o contôrno do orifício escavado, por onde o ar se comunicará do seio frontal para o espaço extradural. Constitui-se então - como aconteceu com nosso doente -- um pneumatocele extradural. Nêsse caso surge cefaléia, que pode, depois, desaparecer, quer espontâneamente, quer quando o osteoma perfurar a dura mater. 0 pneumatocele extradural é raro, como se pode depreender da revisão de Teed ${ }^{8}$ : entre os 321 casos de osteomas de seios paranasais registrados, apenas em duas vêzes (casos de Carmody ${ }^{15}$ e de Benjamins e Ver- 
beek ${ }^{16}$ ) houve formação de pneumatocele extradural. Se considerarmos a pouca freqüência de osteomas dêsses seios, podemos avaliar da excepcional raridade com que se encontram na clínica casos de pneumatocele extradural.

Como nos casos de pneumatocele traumática, é necessário que a pressão do ar intra-sinusal seja superior à da coleção aérea extradural, ou, se a dura mater houver também sido perfurada, da subdural ou mesmo da intracerebral. E' claro que para havér êsse aumento da pressão de ar dentro dos seios frontais deverá haver permeabilidade do duto nas frontais; nessas condições, durante o ato de assoar, de espirrar, de bocejar, ou, mesmo, pela simples expiração, o ar é forçado, sob maior ou menor tensão, para os espaços intra-cranianos. Vêzes há em que a própria expansão do osteoma oblitera o duto nasofrontal e, nêsses casos, a ulterior erosão da parede posterior do seio frontal não poderá determinar a formação de coleção aérea intracraniana. Como, de fato, a obliteração do conduto nasofrontal costuma preceder a erosão da parede posterior do seio frontal, compreende-se a raridade da associação da obliteração daquele duto com um pneumocéfalo (Brunner e Spiesman ${ }^{13}$ ).

Se o osteoma, progredindo em seu crescimento, após haver erosado a parede posterior do seio frontal e se projetado para o interior do espaço extradural, conseguir perfurar a dura mater, produzirá um pneumatocele subdural em que haverá comunicação dos espaços subdurais com as cavidades paranasais.

Nos casos em que a formação do pneumatocele subdural foi devida a traumatismo craniano, a rinorréia é sinal dos mais característicos. Contudo, quando idêntico processo fôr causado por osteomas, a rinorréia já não é obrigatória e, quando presente, costuma ser transitória. Brunner e Spiesman ${ }^{13}$ acreditam que no pneumatocele subdural traumático, verificando-se rotura brusca da dura mater e, conseqüentemente; súbita abertura dos espaços subdurais, haverá, obrigatòriamente, um escoamento do líqüido cefalorraquidiano através das cavidades nasais. Entretanto, nos casos de osteomas, o processo é lento e gradual, de modo a permitir a formação de aderências assépticas que bloqueiam o fluxo de líquor para o nariz. Em outras vêzes, o próprio osteoma, havendo prèviamente obliterado o duto nasofrontal, poderá impedir o vasamento do líquor.

Em estádios ulteriores de sua evolução, o osteoma pode atingir o próprio tecido cerebral, formando um pneumatocele intracerebral, como ocorreu, entre outros, com o caso 4 de Brunner e Spiesman ${ }^{13}$, com o de Heitor Nascimento ${ }^{11}$, com o de Baldenweck, Mallet, Thévenard e Jouveau-Dubreil ${ }^{17}$, com o de E. Tolosa e Duran ${ }^{18}$. Dandy ${ }^{19}$ considerava mesmo o pneumatocele intracerebral como a forma mais freqüente de pneumocéfalo por osteoma de seios paranasais. Essa opinião não foi corroborada pela revisão de Teed que, em 321 casos, encontrou 8 pneumocéfalos, sendo 2 extradurais, 4 subdurais e extracerebrais e 2 ventriculares. $O$ pneumatocele ventricular (casos de Armitage ${ }^{2}$ e de Campbell e Gottschalk ${ }^{20}$ ) é realizado quando a coleção aérea intracerebral atinge e se comunica com o ventrículo lateral. 
Finalmente, outra complicação neurológica rara de osteomas dos seios paranasais é a neurite óptica retrobulbar; mais freqüente em alterações dos seios posteriores (etmóide posterior e seios esfenoidais), pode também ocorrer na vigência de osteomas frontais (Berger ${ }^{21}$ ).

Em nosso caso, vários aspectos interessantes merecem considerações. Primeiramente, a sede extra ou subdural do pneumatocele era problema a resolver antes da operação. As radiografias, principalmente a tomografia, demonstrando a grande proximidade da coleção aérea com a tábua interna do crânio e a evidência do desenho vascular dessa tábua, sugeriam o diagnóstico topográfico extradural. A falta de rinorréia em tôda a evolução da doença não era elemento conclusivo, pelas razões acima expostas. Entretanto, a intervenção cirúrgica revelando a integridade da dura mater e, principalmente, a evolução para a cura completa, permitiram afirmar com segurança da localização extradural do pneumatocele.

Interessante assinalar o resultado do eletrencefalograma que, apesar da interpolação de uma bôlsa de ar entre os elétrodos do hemisfério esquerdo e a córtex, revelou maior amplitude dêsse lado esquerdo em relação aos elétrodos simétricos.

Finalmente, outro aspecto para o qual não encontramos explicação plena, reside na hemiparesia direita apresentada pelo paciente. Parece-nos mais provável que a coleção aérea, através da dura mater e planos subjacentes, exercia ligeira compressão sôbre a superfície do hemisfério esquerdo, suficiente para produzir sua inibição funcional. Reabsorvido o ar, após fechamento cirúrgico da comunicação com o seio frontal, a função cortical se normalizou.

\section{RESUMO}

Os autores relatam o caso de um homem de 38 anos de idade que apresentava uma hemiparesia direita nítida, sem afasia, datando de cêrea de um mês. O déficit motor no dimídio direito se iniciara com violenta cefaléia, rebelde ao uso de analgésicos, mas que, pouco a pouco, cedeu completamente. $\mathrm{O}$ exame clínico não revelou qualquer causa capaz de explicar a hemiparesia. Líqüido cefalorraquidiano e exame oftalmoscópico inteiramente normais. As radiografias simples do crânio mostraram opacificação de consistência compacta no seio frontal e imagem aérea, volumosa, ocupando a maior parte do hemicrânio esquerdo. Os cortes planigráficos sagitais revelaram erosão da parede posterior e do assoalho do seio frontal, sem continuidade com a coleção de ar. Durante a operação foi verificada integridade da dura mater. Dias após a intervenção, a motricidade voluntária do hemicorpo direito já havia melhorado consideràvelmente $\mathrm{e}$, um mês após, o exame neurológico foi totalmente negativo. Tratava-se de osteoma ebúrneo.

Após estudar os aspectos otorrinolaringológicos dos osteomas dos seios frontais, os autores consideram as suas eventuais complicações. Assim, se o tumor crescer para o lado, poderá invadir a órbita, causando exoftalmo, proptose e diplopia; expandindo-se para trás, poderá erosar a parede pos- 
terior do seio frontal, ocasionando pneumatocele extradural, como ocorreu no caso registrado neste trabalho; sucessivamente, poderá também perfurar a dura mater (pneumatocele subdural), invadir o tecido cerebral (pneumatocele intracerebral) e mesmo se comunicar com o ventrículo lateral (pneumatocele ventricular).

Essas coleções aéreas intracranianas (pneumocéfalos) são eventualidades excepcionais em doença também rara. De fato, até 1941, haviam sido registrados 321 casos de osteomas, dos quais apenas 8 se complicaram de pneumocéfalo: 2 extradurais, 4 intracerebrais e 2 ventriculares. Por outro lado, essas complicações neurológicas de osteomas podem se agravar pela inflamação do seio paranasal infectado.

Comparando os casos de pneumatocele subdural traumático com os determinados por osteomas sinusais, os autores chamam a atenção para a inconstância e a transitoriedade com que, nestes últimos, se evidencia a rinorréia cefalorraquidiana.

Para que se forme a coleção aérea intracraniana é necessário que o duto nasofrontal seja permeável; evidentemente, se êste houver sido prèviamente obliterado pela expansão do tumor, o pneumatocele não poderá se constituir.

Os autores explicam a hemiparesia apresentada pelo paciente, como o resultado de uma compressão da coleção de ar, através da dura mater e dos planos subjacentes, sôbre o hemisfério cerebral esquerdo.

\section{SUMMARY}

The authors present a case of a man, 38 years old, who presented since a month a right hemiparesia, without aphasia. The paresia in the right side began with a violent headache, which would not give way to the analgesics, but little by little, disappeared completely. A careful general examination did not show any cause capable of explaining the hemiparesia. Ophthalmologic and spinal fluid examinations were absolutely normal. The plain radiograms shows a opacity of compact consistency in the frontal sinus and a voluminous image occupying the largest part of the left side of the skull. The sagital tomographic sections revealed erosion of the posterior wall and floor of the frontal sinus in continuity with the air collection. Once the patient was operated on, the integrity of the dura mater was evident. A few days after the intervention, the voluntary movements of right side of the body had already improved considerably, and a month later the neurologic examination was entirely negative. The removed tumor was an osteoma eburneo.

After studying the oto-rhino-laryngologic aspects of the osteoma of the frontal sinus the authors consider its eventual complications. If the tumor grows lateral wards, it may invade the orbit, causing exophtalm, proptesis and diplopia; expanding backwards, it may crode the posterior wall of the frontal sinus causing an extradural pneumatocele, as occurred in the case 
registered in the present paper; it may also successively perforate the dura mater (sub-dural pneumatocele), invade the brain tissue (intra-cerebral pneumatocele), and even communicate with the lateral ventricle (ventricular pneumatocele). These intracranial collections (pneumocephalus) are exceedingly rare eventualities in a rare illness. As a matter of fact, until 1941, 32]. cases of "osteomae" had been registered, of which only 8 had complications of pneumocephalus ( 2 extra-dural, 4 intra-cerebral and 2 ventricular). Besides, these neurologic complications of "osteomae" may get worse with inflammation brought from the infected paranasal sinus.

Comparing the cases of traumatic sub-dural pneumatocele with those determined by sinusal "osteomae" the authors emphasize the inconstancy and transitoriness with which, in the last ones, the rhinorrhea is present.

The naso-frontal duct must be permeable to allow the formation of intracranial aerial collection; evidently if this one has been previous ohliterated by the expansion of the tumor, the pneumatocele cannot be produced.

The authors explain the hemiparesia presented by the patient, as the result of a compression by the air collection, through the dura mater and the subjacent plans, on the left cerebral hemisphere.

\section{BIBLIOGRAFIA}

1. Novick, J. N. - Osteoma of the frontal sinus. Arch. Otolaryng., 46:655-669 (novembro) 1947.

2. Armitage, G. - Osteoma of the frontal sinus: with particular reference to its intracranial complications, and with the report of a case. Brit. J. Surg, 18: 565-580 (abril), 1931 .

3. Patriarca e Rosello - Cit. por Armitage 2.

4. Childrey, J. H. - Cit. por Eggston, A. A. e Wolff, D. - Histopathology of the Ear, Nose and Throat. Williams a. Wilkins, Baltimore, 1917.

5. Begley, Y. W. e Hallberg, O. E. - Osteoma of the paranasal sinuses and their treatment. Proc. Staff Meet., Mayo Clin., 25:13, 1950.

6. Smith, A. T. - Osseous lesions of nose and sinuses: with special reference to hypertrophicchanges and tumor formations. Arch. Otolaryng., 31:289, 1940.

7. Beck, J. C. - Cit. por Armitage 2.

8. Teed, R. W. - Primary osteoma of the frontal sinus. Arch. Otolaryng., 33: 255-292 (fevereiro), 1941 .

9. Sanson, D. - Discussão a propósito da comunicação de Renato Machado 1n.

10. Machado, R. - Osteoma das cavidades perinasais. Bol. Col. brasil. de Cirurgiões, 16:143-156 (dezembro), 1941.

11. Nascimento, H. - Osteoma fronto-etmoidal e pneumatocele. Arq. Inst. Penido Burnier, 7:161-167 (dezembro), 1945.

12. Pereira, C. -- Discussão a propósito da comunicação de Renato Machado 10.

13. Brunner, H. e Spiesman, I. G. - Osteoma of the frontal and ethmoid sinuses. Ann. Otol. Rhin. a. Laryng., 57:714-737 (setembro), $19+8$.

14. Cushing, H. - Experiences with orbito-ethmoidal osteoma having intracranial complications. Surg., Gynec. a. Obst., 44:721-742 (julho), 1927.

15. Carmody, T. E. - Cit. em Teed, R. W.8. 
16. Benjamins, C. E. e Verbeek, F. A. L. - Pneumatocele frontale interne et ostéome du sinus frontal. Ann. d’Oto-laryng., págs. 881-892, 1936.

17. Baldenweck, Mallet, Thévenard e Jouveau-Dubreil — Pneumatocele frontale interne, au cours de l'évolutions d'un ostéome du sinus frontal. Ann. d'Otola ryng., 11:658-668 (julho), 1934 .

18. Tolosa, E. e Duran, F. - Ostéome fronto-ethmoido-orbitaire compliqué d'empyème des sinus frontaux. Extirpation radicale par voie transfrontale. Rev. Neurol., 81:144-147 (fevereiro), 1949.

19. Dandy, W. E. - Pneumocephalus (intracranial pneumatocele or aerocele). Arch. Surg., 12:949-982 (maio), 1926.

20. Campbell, E. H. e Gottschalk, R. B. - Osteoma of frontal sinus and penetration of lateral ventricle, with intermittent pneumocephalus. J.A.M.A., 111: 239-241 (julho), 1938.

21. Berger, M. -- Névrite optique retro-bulbaire et cstéome du sinus frontal. Rev. d'oto-neuro-opht., 22:523-528 (agôsto-setembro), 1950

22. Berger, M. - Les osteomes des sinus pericraniens. Rev. de Laryng., 71 :301, 1950 .

Serviço de Neurologia -- Hospital das Clinicas - São Pcinlo. 